\title{
Droop Control Based Grid-Connected Solar Photovoltaic Inverters for Distributed Generation
}

\author{
Praiselin W. J., J. Belwin Edward
}

\begin{abstract}
In day to day the demand of electrical energy has been increasing in worldwide, as well the share of solar photovoltaic power generation has increased extremely because of population growth, urbanization, etc. Although the power generated from solar photovoltaic is erratically, and it makes the stability and reliability problems in a utility grid. This paper projects a $P / Q$ droop control strategy for a grid-tied PWM inverter. This paper introduces an entire model of grid-connected solar photovoltaic array; inverter with droop control, and loads are developed for this operation. The locus points of the both power sharing of the DG system is developed by the proposed control operation. PI controllers were used in this droop control was espoused to adjust the constraints of PI controller. The results of the proposed droop control inject positive and reactive power into a variation of loads and improving the quality of power as compared to the conventional PID controllers.
\end{abstract}

Keywords: distributed generation, droop control, power quality, solar photovoltaic.

\section{INTRODUCTION}

$\mathrm{I}_{\mathrm{n}}$ ncreasing the population and therefore the industrial sector within the developing countries, the consumption of electrical power has been increasing quite 50\% in 2035 compared to the year of 2008. Challenges like environmental crisis, increasing the power system consistency, and therefore the energy demand has caused the approach of the distributed generation (DG) and the microgrid (MG) [1]. At present, the energy division affected due to provide low fuel and capacity to the power plant; therefore load shedding can come back automatically. The renewable energy sources (RES), photovoltaic (PV) have one in all the most effective solutions for producing the electrical power due to the solar radiation and it provides various merits such as clean and energy independence, eco-friendly with the extra advantages of low maintenance, no moving elements, easy to implement and zero fuel price [2]. During the peak power generation, integration of grid-tied PV systems needs to be playing some challenges that supported these benefits. The maximum quantity of power is generated from the PV that's delivered into the electrical grid. Therefore, this may be operated at the unity power factor and achieved by positive power control [3]. Till 2050, the usage of electrical energy of solar PV itself is only $11 \%$. This information was calculated from the International Energy Agency. Also united states allow distributed PV with $15 \%$ of peak power to be permitted on the

Revised Manuscript Received on December 04, 2019

* Correspondence Author

J. Belwin Edward*, SELECT, Vellore Institute of Technology, India. Email: jbelwinedward@vit.ac.in

Praiselin W. J., SELECT, Vellore Institute of Technology, India. Email: jbelwinedward@vit.ac.in feeder. Whereas, IEEE STD 1547 utilizes the capability of reactive power, expanding the $\mathrm{PV}$ penetration and voltage regulation will be lead to the global policy.

Conversely, this PV system is assessed by low, medium, and a high wattage generation, its applications to medium and high electrical power generation, solar PV ought to be connected to grid with power electronic inverters. Although the phase difference between the integration of grid and the inverters verified due to the enhancement of the quality of power, low current ripple, modularity, and easily maintain the system, also the features of grid-connected inverters are positive power, voltage harmonic distortion, voltage regulation, inverter output amplitude and phase, stable, and reliable operation of the system [4]. In the past decades, various closed-loop system management techniques are studied. Predominantly, grid-connected solar PV has been employed in different controllers like proportional-integral controller (P-IC), proportional-integral and derivative controller (P-IDC), proportional-resonant controller (P-RC) [6], robust control, feed-forward control, adaptive control, repetitive control [5], optimization and intelligent control [7]. Among the above-mentioned controllers, droop control has demonstrated its good performance, and it offers a much better control compared to the linear controllers.

Droop Control (DC) methods that imitate the qualities of the traditional synchronous machine on the transmission level [8]. Droop control strategies of DG are scrutinized for numerous combinations of RES in MG. Various PWM techniques like unipolar PWM which is used to regulate the inverter operation. In the literature [9]-[11], voltage and frequency droop control technique is utilized to manage the grid integration of PWM inverter that wishes positive-reactive power to be computed to droop the voltage and frequency level. Additionally, the injected current is controlled by regulating the angle power, and there is no direct control of power compared to the conventional grid-connected inverters. $\mathrm{P} / \mathrm{f}$ droop control depends on the frequency level of the grid system and $\mathrm{Q} / \mathrm{V}$ droop control depends on the power level by the coupling of the point. By looking at these controllers, this type of control is repetitively affected by the combined source of resistance in ohmic value and reactance level of the DG.

This paper presents the distributed generation control strategy for grid-connected solar photovoltaic inverters based on droop control has been studied. The PV system has to be inter-connected to the electrical grid through 3-phase inverters and a DC converter.

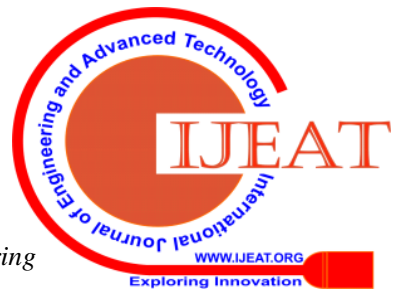


$\mathrm{P} / \mathrm{Q}$ droop control is proposed. The switching pulses are measured by a pulse width modulation technique. Also, the droop control frequency has been measured. The grid-connected solar PV systems results are taken by a PWM inverter with droop control have improved the power of the grid side.

The sections of this paper are given below: Section 2 by exploring the overall PV system concept. Section 3 presents the mathematical modeling and one diode model of solar PV system. Section 4 and 5 presents the inverter operation of a grid-connected PV system and proposed control method by a PWM inverter. Section 6 presents the results of the proposed droop control and section 7 gives concluding remarks.

\section{GRID-CONNECTED SOLAR PV CONCEPT}

The droop control with solar PV system is inter-connected to the electrical utility grid is illustrated as Fig. 1. Here the main source is the PV system which generates electrical power from the solar system. The solar PV array is directly linked to the power grid through the inverter, then the inverter converts DC to AC supply. Here the PWM inverter is employed and it generates the pulses in every switch. During the normal and abnormal conditions, the parameters of the power flow can be given by a stable level in the grid-connected solar PV system [12]-[13]. The positive (P), reactive $(\mathrm{Q})$ power of the grid are often evaluated by using the parameters like voltage and current of the electrical grid. Equations (1) and (2) of P, Q dispatched to the grid can be illustrated by given below.

$$
\begin{aligned}
& P=\frac{1}{2} v_{g}^{d} i_{g}^{d} \\
& Q=-\frac{1}{2} v_{g}^{d} i_{g}^{d}
\end{aligned}
$$

The grid PQ problem is categorized the calculation of error between the actual value and the reference value of grid parameters.

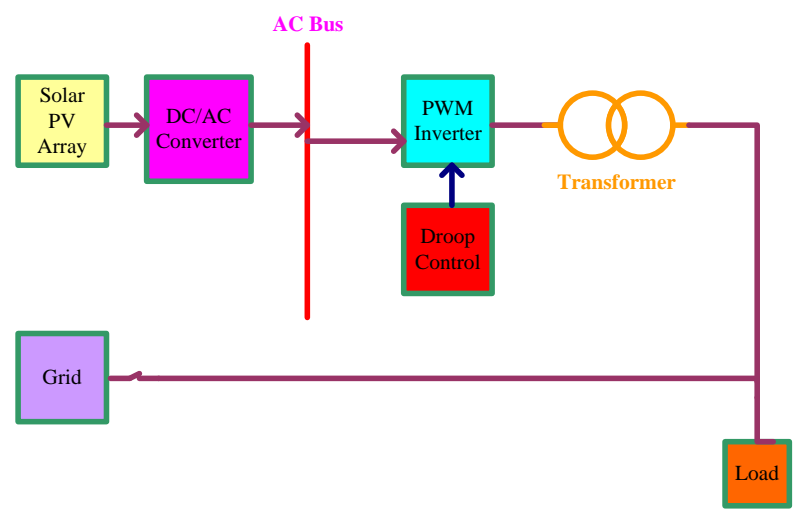

Fig. 1. Grid tied solar PV system concept.

The error calculation of $\mathrm{P}, \mathrm{Q}$ power can be expressed as (3) and (4).

$$
\begin{gathered}
\Delta P=\left[P_{a c t}-P_{r e f}\right] \\
\Delta Q=\left[Q_{a c t}-Q_{r e f}\right]
\end{gathered}
$$

Where, $\Delta P, \Delta Q$ are the change in the error values of positive and reactive power.

$\mathrm{P}_{a c t}, \mathrm{Q}_{a c t}$ are the actual power of $\mathrm{P}$ and $\mathrm{Q}$.
$\mathrm{P}_{\mathrm{ref}}$ and $\mathrm{Q}_{r e f}$ are the reference value of $\mathrm{P}$ and $\mathrm{Q}$.

\section{MATHEMATICAL MODELING OF SOLAR PV}

The PV cells are connected in nonparallel or parallel which provides the well-liked output voltage and current. In this paper, we have to decide on one diode with a photo current supply. According to Fig. 2, every PV cell is made by a generated phase current $I_{p h}$, a parallel-connected diode $I_{d}$, reverse saturation current $I_{s h}, R_{s}$ and $R_{s h}$ are represented by the series and parallel resistance of one diode model.

The mathematical equation [14] from the one diode model of the solar PV is given by (5),

$$
I_{p v}=N_{p}-N_{p} I_{s}\left[\exp \left[\left(\frac{q}{n k T}\right)\left(\frac{V_{p v}}{N_{s}}+\frac{I_{p v} R_{s}}{N_{p}}\right)\right]-1\right]-\frac{N_{p}}{R_{p}}\left(\frac{V_{p v}}{N_{s}}+\frac{I_{p v} R_{s}}{N_{p}}\right)
$$

Where $k$ is the constant value of Boltzmann's and the value is noted as $\left(1.4 \times 10^{-23}\right)$, and $T$ is the temperature noted by Kelvin.

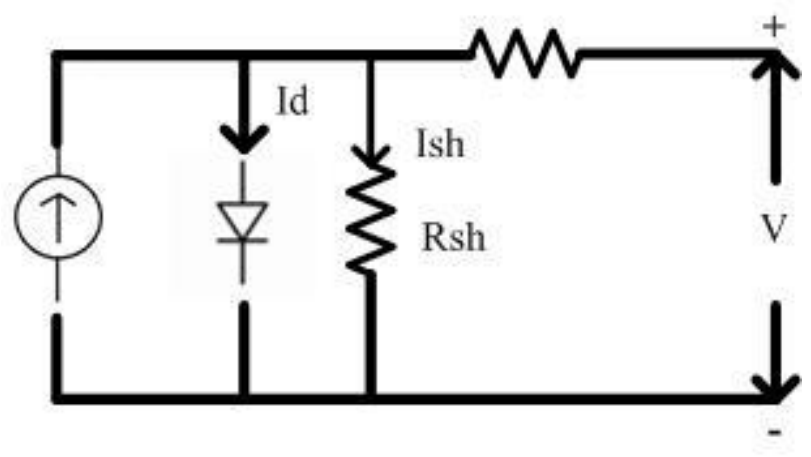

Fig. 2. Single diode modeling of solar PV.

\section{INVERTER OPERATION}

In this paper, a primary part of the PWM electrical inverter topology has been explained as Fig. 3. The PV array interfaces the grid through DC link and PWM inverter. The major role of the inverter is used for converting $\mathrm{DC}$ to $\mathrm{AC}$ power [15]. Generally the three phase inverter switching power devices consists of one, two or three arms. In the inverter design, researchers mainly considered a load imbalance problem in the system. The inverter topology consists switches (S1-S6), $\mathrm{R}_{\mathrm{f}}$ are the filter resistance, and three phases $\left(\mathrm{e}_{\mathrm{an}}, \mathrm{e}_{\mathrm{bn}}, \mathrm{e}_{\mathrm{cn}}\right)$, each phase is individually controlled the system.

In the second part, the droop control method has been explained briefly. The measured value of $\mathrm{P}$ and $\mathrm{Q}, \mathrm{P}^{*}$ and $\mathrm{Q}^{*}$ are locus point, nominal voltage $\mathrm{V}^{*}, \mathrm{f}^{*}$ are minimal voltage and frequency. Generally this element are considered as the input values which have to be calculated by using the droop control that is the reference frequency $\left(\mathrm{f}_{\mathrm{ref}}\right)$ and reference voltage $\left(\mathrm{V}_{\text {ref }}\right)$ [16]. Fig.4 has been demonstrated the characteristic curve of droop control.

Published By: Blue Eyes Intelligence Engineering \& Sciences Publication 


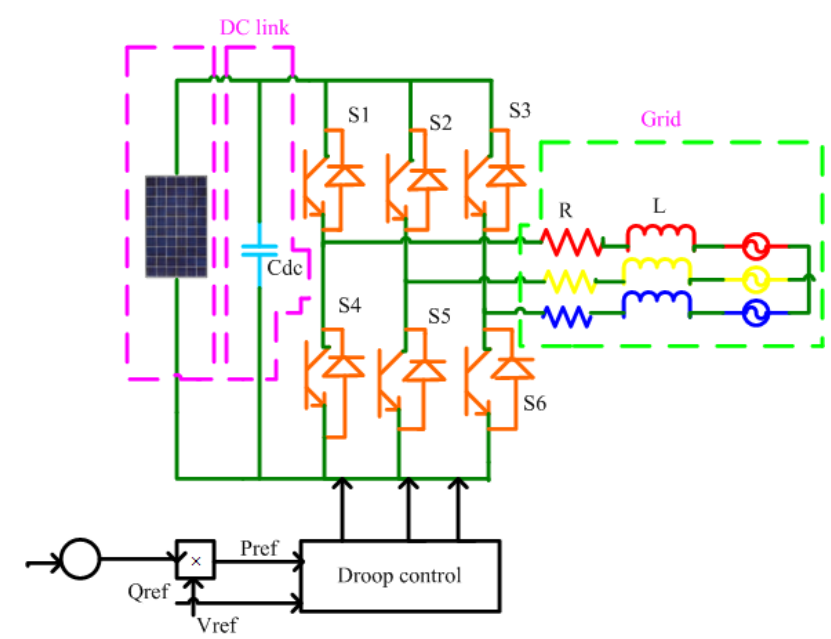

Fig. 3. Grid tied PV system with PWM inverter controller operation.

Fig. 4 has been demonstrated the characteristic curve of droop control. Also, the equation of power and frequency droop control will be given by,
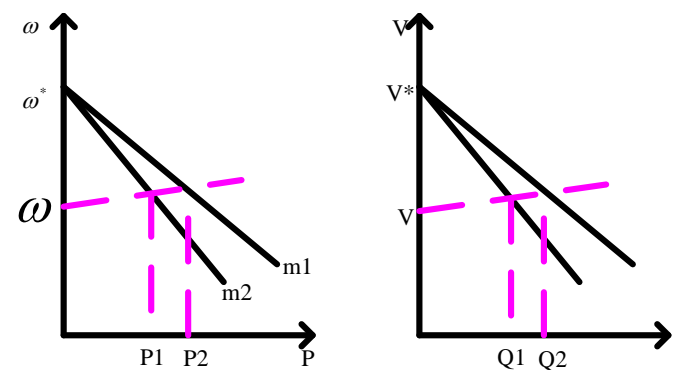

Fig. 4. Diagram of droop curve.

$$
\begin{aligned}
& \omega=\omega^{*}-m\left(P-P^{*}\right) \\
& V=V^{*}-n\left(Q-Q^{*}\right)
\end{aligned}
$$

In the above equations, $\omega$ and $V$ represents the reference value of the droop control; $m$ and $n$ are represented the slope values of droop. Generally, power demand of each and every DG shares based on the characteristic function of droop control. In the droop characteristic curve, $\omega$ and $V$ is generating the stable or linear point and this slope could distribute the low power.

\section{PROPOSED CONTROLLER OPERATION}

The proposed P/Q droop control can be operated when the inverter is connected in grid connection mode. Inverter side $\mathrm{P}$ and $\mathrm{Q}$ power can be determined by various approaches. The power injecting into the electrical grid, which is pre-specified by centrally or locally connected systems. The P/Q droop equation can be illustrated as given below ,

$$
\begin{aligned}
& P=P_{o}+K_{f p}\left(f_{o}-f\right) \\
& Q=Q_{o}+K_{v Q}\left(V_{o}-V\right)
\end{aligned}
$$

Fig. 5 shows the proposed droop with P/Q control, and this technique has to be considering two loops. Each loop consists of positive power of locus value $\left(\mathrm{P}_{\text {ref }}\right)$, reactive power of locus value $\left(Q_{\text {ref }}\right)$, and measured values. In loop $1, P_{\text {ref }}$ is calculated with $\mathrm{Q}_{\text {actual }}$ and the error might be providing for the PI controller 1 . Then the terminal voltage $v_{t}$ is multiplied and the outputs of the locus voltage $v_{c 1}{ }^{*}$ have received from the phase terminal voltage. In loop 2 , the locus value of positive power $\mathrm{P}_{\text {ref }}$ and the error might be fed to the PI controller 2 which generates the phase shift $\alpha_{1}{ }^{*}$ and it equally balancing the positive power output from both $\mathrm{AC}$ and DC side. The equations of $v_{c 1}{ }^{*}, \alpha_{1}{ }^{*}, \alpha_{2}{ }^{*}$ and $\alpha^{*}$ are illustrated by (10), (11), (12), (13). In addition, PWM technique is used to generate the pulse signals. The proposed P/Q droop control with two PI controllers is reduced the positive and reactive power level.

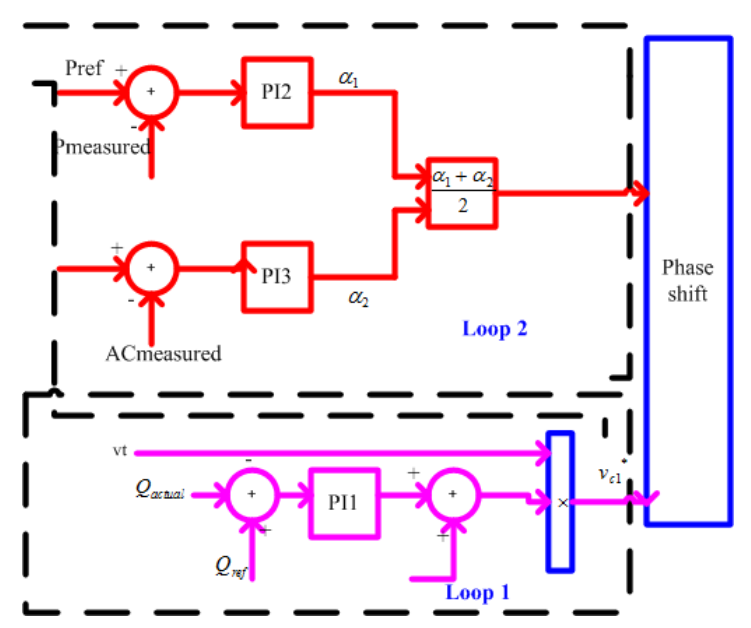

Fig. 5. P/Q inverter droop control.

$$
\begin{aligned}
& v_{c 1}{ }^{*}=\left(K_{p 1}\left(Q_{\text {ref }}-Q_{\text {actual }}\right)+K_{I 1} \int_{0}^{t}\left(Q_{\text {ref }}-Q_{\text {actual }}\right) d t+1\right) v_{t}(10) \\
& \alpha_{1}^{*}=K_{P 2}\left(P_{\text {ref }}-P_{\text {actual }}\right)+K_{I 2} \int_{0}^{t}\left(P_{\text {ref }}-P_{\text {actual }}\right) d t
\end{aligned}
$$

$$
\begin{gathered}
\alpha_{2}^{*}=K_{P 3}\left(1.02 * P_{A C \text { measured }}-P_{D C}\right)+K_{I 3} \int_{0}^{t}\left(1.02 * P_{A C \text { measured }}-P_{D C}\right) d t \\
\alpha^{*}=\left(\alpha_{1}^{*}+\alpha_{2}^{*}\right) / 2
\end{gathered}
$$

\section{SIMULATION OUTCOMES AND DISCUSSION}

To verify the value of the solar PV with the grid- connected inverter, P/Q droop controls were simulated by MATLAB Simulink SimPowerSystems platform. Table 1 demonstrates the key parameters and values. Solar PV connects to the grid with P/Q droop control has been shown in Fig.1. To generate $\mathrm{P}$ and $\mathrm{Q}$ power with respect to reference values. Fig. 6 shows the $\mathrm{P}$ and $\mathrm{Q}$ power when the inverter is not connected to the droop control. On-time $0.1 \mathrm{~ms}$, the load voltage is 110 volts. Fig. 7 shows that the switching pulses of the PWM generator. 
Fig. 8 shows that the injected positive and reactive power from the solar PV inverter which can be regulating the voltage and frequency. In this case, frequency is maintained at $50 \mathrm{~Hz}$.

Fig. 9 shows that the $3^{\text {rd }}$ order harmonic injected to the inverter on time $0.5 \mathrm{~ms}$. The injected harmonic level is $0.15 \%$. Fig.10a) shows that the line voltage Vab. Fig.10b) shows the DC link voltage of solar PV. The imported power caused by the voltage level is $677.7 \mathrm{~V}$.

\section{Table- I: Key specifications}

\begin{tabular}{|l|l|}
\hline \multicolumn{1}{|c|}{ Parameters } & \multicolumn{1}{c|}{ Values } \\
\hline Solar PV power & $80 \mathrm{~kW}$ \\
\hline Maximum PV power & $135 \mathrm{~W}$ \\
\hline Maximum PV voltage & $70.4 \mathrm{~V}$ \\
\hline Maximum PV current & $1.93 \mathrm{~A}$ \\
\hline OC voltage & $86.8 \mathrm{~V}$ \\
\hline SC current & $2.02 \mathrm{~A}$ \\
\hline Filter capacitor $\left(\mathrm{C}_{\mathrm{f}}\right)$ & $10 \mathrm{uf}$ \\
\hline Filter inductor $\left(\mathrm{L}_{\mathrm{f}}\right)$ & $0.01 \mathrm{H}$ \\
\hline Frequency & $50 \mathrm{~Hz}$ \\
\hline Switching frequency & $20 \mathrm{kHz}$ \\
\hline DC link capacitor & $1 \mathrm{e}-6$ \\
\hline Grid voltage & $155 \mathrm{~V}$ \\
\hline
\end{tabular}
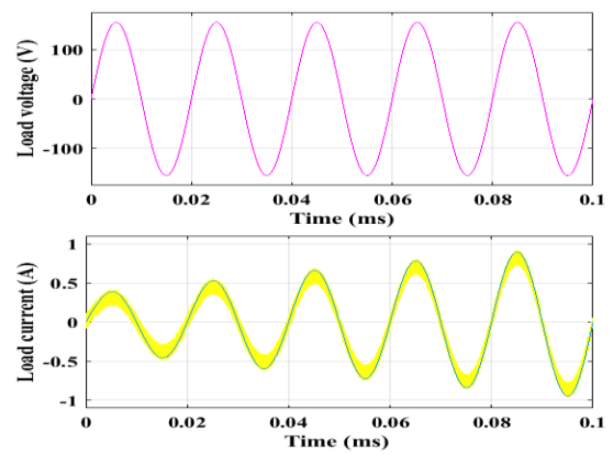

Fig. 6. Load voltage and current without droop control.
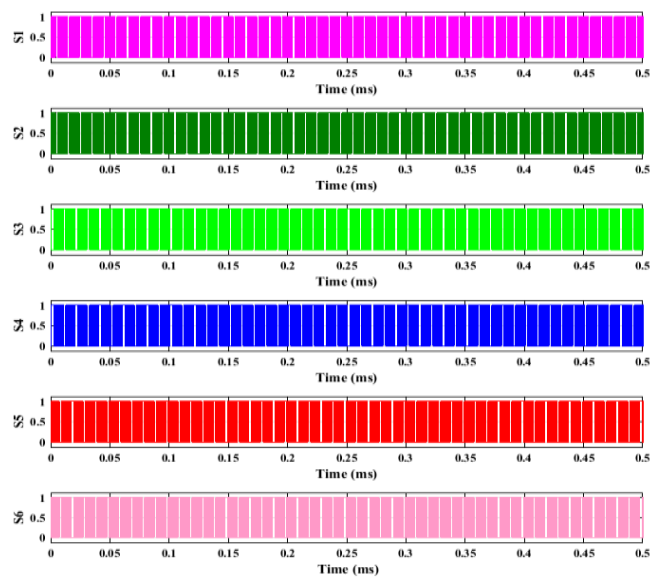

Fig. 7. PWM inverter switching pulses.

Fig.11 represents the load side voltage and current through the system. Fig. 12 demonstrates the line voltage with droop control. Here the voltage level is rising from 0 to $180 \mathrm{~V}$.

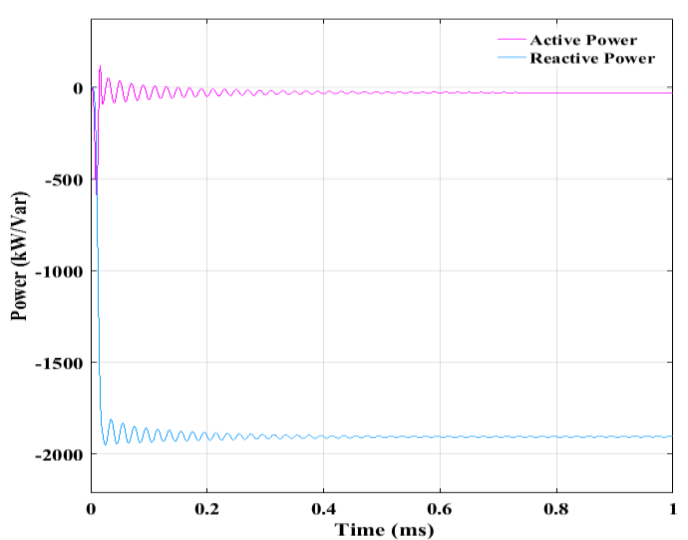

Fig. 8. positive and reactive power with control.

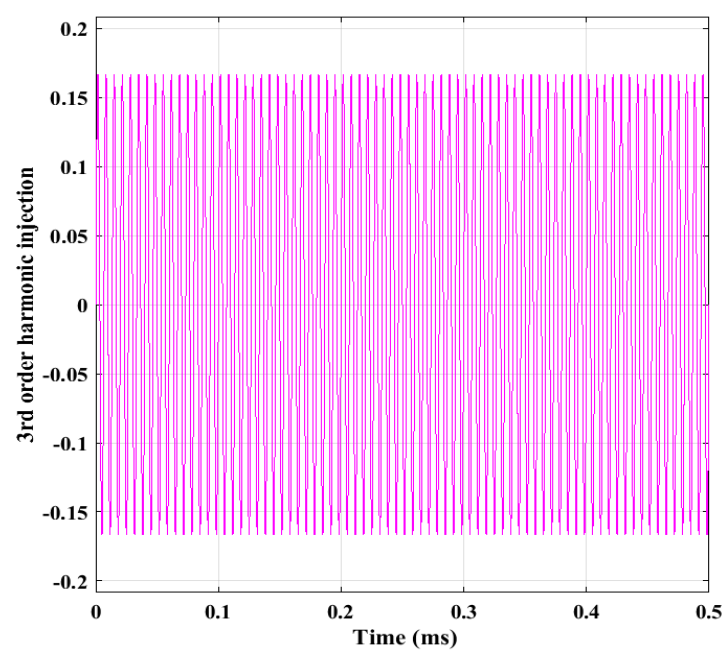

Fig. 9. Injected $3^{\text {rd }}$ order harmonics.
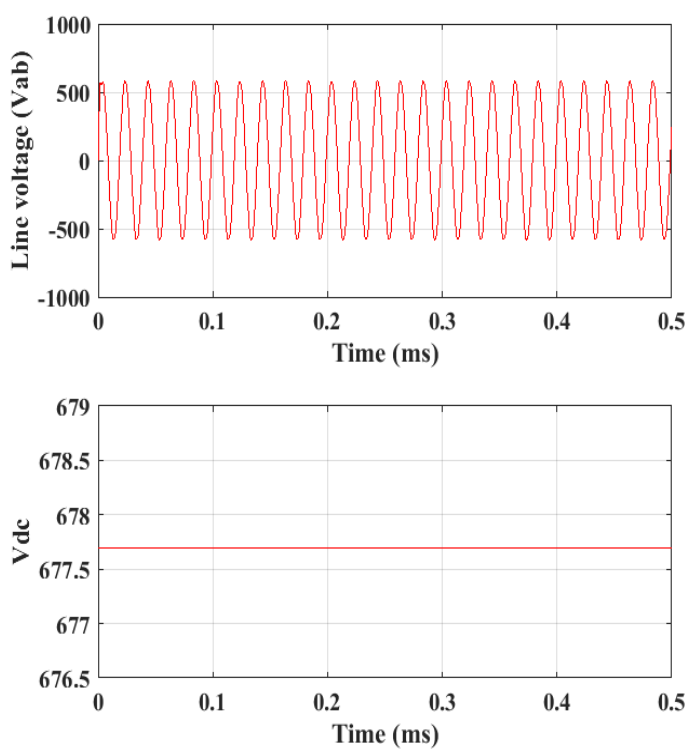

Fig. 10. a) Line voltage, b) DC link voltage.

Published By:

Blue Eyes Intelligence Engineering \& Sciences Publication 

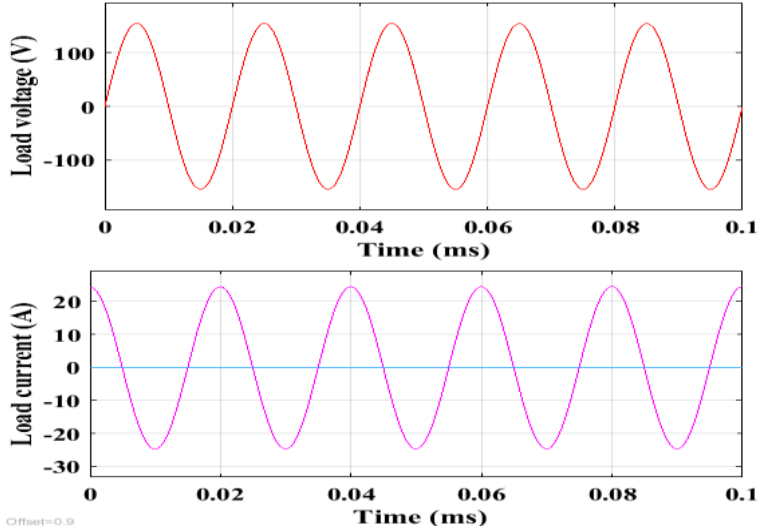

Fig. 11. Load voltage and load current.

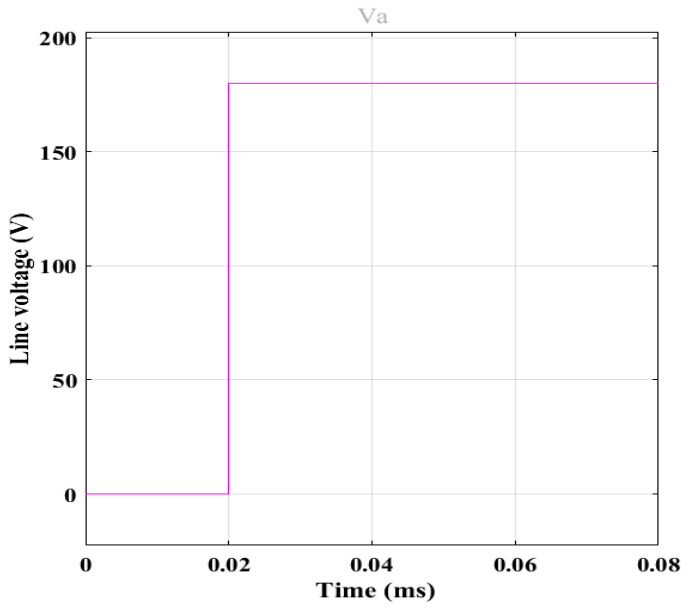

Fig. 12. Line voltage with droop control.

Thus from the simulation results, it had been determined that the P/Q droop control strategy of the grid-connected solar PV system, improves the positive and reactive power compared to the conventional control methods.

\section{CONCLUSION}

A distributed generation control strategy for grid-tied solar PV inverters based on droop control has been presented. The solar PV with PWM inverter was presented and demonstrated in the Simulink/ MATLAB platform. The PI and PID controllers cannot improve the stability and the response of the voltage deviation. However, compared to the PID controller and other conventional controllers, the proposed P/Q droop control is the highest ability to operate between the system operations. The simulation result shows that better performance in positive and reactive power, voltage improvement during the grid- connected solar PV system.

\section{REFERENCES}

1. S. M. Moosavian, N. A. Rahim, and J. Selvaraj, “Energy policy to promote photovoltaic generation," Renewable and Sustainable Energy Reviews, vol. 25, Sep. 2013, pp.44-58.

2. N. Prabaharan, and K. Palanisamy, " A single phase grid connected hybrid multilevel inverter for interfacing photo-voltaic system," Energy Procedia, vol. 103, Dec. 2016, pp. 250-255.

3. E. Bullich Massagua, M. A. P. Nalpa, A. Sumper, and O. Boix Aragones, “ Active power control in a hybrid PV-storage power plant for frequency support," Solar Energy, vol. 144, Mar. 2017, pp. 49-52.
4. P. Monica, and M. Kowsalya, "Control strategies of parallel operated inverters in renewable energy applications: A review," Renewable and Sustainable Energy, vol. 65, Nov. 2016, pp. 885-901.

5. W. J. Praiselin, and J. Belwin Edward, “A review on impacts of power quality, control and optimization strategies of integration of renewable energy based microgrid operation," International Journal of Intelligent Systems and Applications, vol. 3, Mar. 2018, pp. 67-81.

6. S. Messalti, A. Harrag, and A. Loukriz, “ A new variable step size neural networks MPPT controller: review, simulation and hardware implementation," Renewable and Sustainable Energy Reviews, vol. 68, Feb. 2017, pp.221-233.

7. Yancheng Liu, Qinjin Zhang, and Chuan Wang, " A control strategy for microgrid inverters based on a adaptive droop controls," Electric Power Systems Research, vol. 117, Dec. 2014, pp. 192-201.

8. Xisheng Tang, Xiao Hu, Ningning Li, Wei Deng, and Guowei Zhang, “ A novel frequency and voltage control method for islanded microgrid based on multi energy storages," IEEE Trans. On Smart Grid, vol. 7, no.1, Jan. 2016, pp. 410-419.

9. J. He, Y. W. Li, and M. S. Munir, “A flexible harmonic control approach through voltage-controlled DC-grid interfacing converters," IEEE Trans. On Industrial Electronics, vol. 59, no.1, Feb. 2012, pp. 444-455.

10. Mohammad A. Abusara, Suleiman M. Sharkh, and Josep M. Guerrero, “ Improved droop control strategy for grid-connected inverters," Sustainable Energy, Grid and Networks, vol. 1, Mar. 2015, pp. 10-19.

11. B. G. Sujatha, and G. S. Anitha, "Enhancement of PQ in grid connected PV system using hybrid technique," Ain Shams Engineering Journal, vol. 9, no. 4, Dec 2018, pp. 869-881.

12. Yang Yongheng, and Blaabjerg Frede, " Low-voltage-ride-through capability of a single stage single-phase photovoltaic system connected to the low-voltage grid," International Journal of Photoenergy, vol. 2013, no. 1 , Feb. 2013 , pp. 1-9.

13. Nejib Hamrouni, Moncef Jraidi, Ahmed Dhouib, and Adnen Cherif, “ Design of a command scheme for grid connected PV systems using classical controllers," Electric Power Systems Research, vol. 143, Feb 2017, pp. 503-512.

14. Rameen, and Abdel hady, " Modeling and simulation of a microgrid-connected solar PV system," Water Science, vol. 31, no. 1, April. 2017, pp. 1-10.

15. Wenlei Bai, Kwang Lee, "Distributed generation system control strategies in microgrid operation,” IFAC Proceedings Volumes, vol. 47, no. 3, 2014, pp. 11938-11943 [19 ${ }^{\text {th }}$ World Congress, IFAC].

16. Soha Mansour, Mostafa I. Marei, and Ahmed A. Sattar, “ Droop based control strategy for a microgrid,” Global Journals Inc., USA, vol.16, July. 2016, pp. 1-9.

\section{AUTHORS PROFILE}

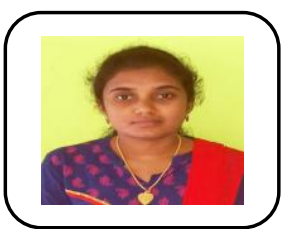

W. J. Praiselin is a doctoral student at the SELECT at Vellore Institute of Technology, Vellore, India. Her research interests include power quality improvement in microgrids, integration of renewable energy sources. She has published 5 Scopus Indexed journals. She is the reviewer of the International Journal of Artificial Intelligence and also she is a member of IAENG.

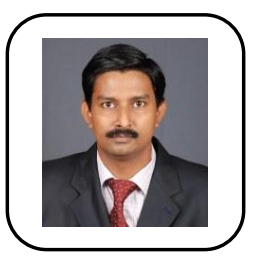

J. Belwin Edward is an Associate Professor of Vellore Institute of Technology, Vellore, India. He received a $\mathrm{PhD}$ degree in the Department of Electrical Engineering from Anna University, Chennai in 2013. His research includes areas of Power system Optimization and protection, Renewable Energy Systems. He is the organizing chair of two international conferences (International Conference on Innovations in Power and Advanced Computing Technologies, 2017 \& 2019, IEEE). He has published more than 35 peer-review research articles and one book chapter. 